\title{
Kata al-Ikhlash dalam Alquran: Kajian Semantik
}

\author{
Miftahur Rahman \\ UIN Sunan Kalijaga, Yogyakarta \\ mitahurrahmanqudsy@gmail.com
}

DOI: http://dx.doi.org/10.29240/alquds.v2i2.476

Submitted: 2018-07-10 | Revised: 2018-11-07| Accepted: 2018-11-22

\begin{abstract}
This paper discusses the term khalasha and its derivation in the Quran. This study uses the semantic theory of the Quran Toshihiko Izutsu. First, discuss the basic and relational meaning. Second, perform syntactic and paradigmatic analysis. Third, perform synchronic and diachronic analysis of the term khalasha. Synchronic and diachronic analysis discusses the term from pre-Quran, Quranic (revelation) era, until post-Quran era. Fourth, find weltanschanung the use of khalasha and its derivation in the Quran. The result of this research is the basic meaning of khalasha is pure. The relational meaning is purifying, special, clean, jarring, and clear. There are two different concepts of the use of the khalasha term and its derivation in the Quran. First, the term includes about the concept of religion which means to keep religion. Second, if connected with a thing then its meaning is clean.
\end{abstract}

Keywords: Ikhlas; khalasha; Semantics; the Quran.

Absrak.Tulisan ini membahas tentang lafaz khalasha dan derivasinya dalam Alquran. Kajian ini menggunakan teori semantik Alquran Toshihiko Izutsu. Pertama, membahas makna dasar dan relasional. Kedua, melakukan analisis sintakmatik dan paradigmatik. Ketiga, melakukan analisis sinkronik dan diakronik terhadap term khalasha. Analisis sinkronik dan diakronik membahas kata tersebut dari pra Alquran, era Alquran, dan era pasca Alquran. Keempat, menemukan weltanschaumng penggunaan khalasha dan derivasinya dalam Alquran. Hasil penelitian ini ialah makna dasar dari khalasha ialah murni. Sedangkan makna relasionalnya ialah memurnikan, khusus, membersihkan, mengesakan, dan jernih. Terdapat dua konsep yang berbeda dari penggunaan term khalasha dan derivasinya dalam Alquran. Pertama, term khalasa mencakup tentang konsep agama yang berarti menauhidkan agama. Kedua, jika dihubungkan dengan benda, maka maknanya adalah membersihkan.

Katakunci: Ikhlas; khalasha; Semantik; Alquran 
106 | AL QUDS : Jurnal Studi Alquran dan Hadis vol. 2, no 2, 2018

\section{Pendahuluan}

Penafsiran terhadap Alquran selalu mengalami perkembangan dan pergeseran. Berbagai pendekatan dalam usaha untuk memahami maksud Tuhan telah dilakukan oleh para cendekiawan Muslim. ${ }^{1}$ Dewasa ini, para cedekiawan melakukan kajian terhadap Alquran dengan beragam perspektif. Semisal perspektif ilmu sosial, sains, psikologi, sejarah dan lain-lain. Amīn al-Khūllī menyatakan bahwa sebelum Alquran dikaji dengan ilmu-ilmu tersebut, terlebih dahulu diperlukan analisis secara linguistik dan sastra Alquran. ${ }^{2}$ Hal tersebut sangat diperlukan, sebab Alquran diturunkan dengan menggunakan bahasa Arab. Maka, studi terhadap kebahasaan menjadi sangat penting untuk memahami Alquran.

Berbicara tentang teks bahasa Alquran, Nashr Hāmid Abū Zaid mengatakan bahwa teks merupakan produk budaya. ${ }^{3}$ Artinya, terbentuknya sebuah teks tidak bisa dipisahkan dari budaya dan realitasnya. Oleh karena itu, untuk memahami Alquran dibutuhkan pemahaman terhadap bahasa Arab 14 abad yang lalu. Realitas 14 abad yang lalu tidak bisa disamakan dengan realitas hari ini. Oleh karena itu, pemaknaan terhadap sebuah teks bisa jadi mengalami perkembangan bahkan perubahan karena realitasnya juga berbeda. Hal ini tentu juga berakibat terhadap pemaknaan teks Alquran itu sendiri.

Seperti dalam kasus nama surat yang ke-112 dalam Alquran yakni alIkhlash. Makna ikhlas menurut KBBI (Kamus Besar Bahasa Indonesia) yakni bersih hati; tulus hati. Seperti kata ikhlas dalam kalimat "kami telah mengikhlaskan kepergiannya" yang berarti memberikan atau menyerahkan dengan tulus hati. Apabila makna versi KBBI tersebut dipakai untuk memaknai surat al-Ikhās maka akan tampak tidak koheren antara nama surat dengan isi kandungannya. Isi kandungan surat al-Ikhlash berbicara tentang ketauhidan atau keesaan Allah.

Oleh karena itu, diperlukan kajian terhadap kata dalam ikhlash Alquran. Untuk itu, dibutuhkan pendekatan yang dapat menjawab bagaimana kata ikhlash dipahami oleh generasi pertama atau generasi zaman Nabi saw. Kata ikhlash dalam Alquran hanya muncul satu kali yakni dalam nama surat ke 112 tersebut. Akar kata dari ikhlash (إخلاص) yakni khalasha (خلص). Tulisan ini membahas

${ }^{1}$ Wahyu Hanafi, "Linguistik Al-Qur'an (Reinterpretasi Makna Manusia Di Balik Surat AlFâtihah Dalam Wacana Semantik)," Studia Quranika: Jurnal Studi Quran 2, no. 1 (2017): 2, doi:10.21111/studiquran.v2i1.1131.

2 Amin al-Khulli, "Tafsir," in Pemikiran Hermenentika Dalam Tradisi Islam: Reader, by Syafaatun Mirzanah and Sahiron Syamsuddin (Yogyakarta: Lembaga Penelitian, UIN Sunan Kalijaga, 2011), 231.

${ }^{3}$ Nasr Hamid Abu Zaid, Tekstualitas Alquran: Kritik Terbadap Ulumul Quran (Yogyakarta: LKis, 2001), 22. 
tentang kata ikblash dalam Alquran dengan menelaah kata khalasha dan derivasinya dalam Alquran. Untuk membantu mempermudah kajian ini, penulis menggunakan teori semantika Alquran Toshihiko Izutsu.

\section{Teori Semantik Alquran Toshihiko Izutsu}

Semantik adalah studi tentang makna. Menurut pandangan umum, semantik merupakan kajian yang menyangkut hubungan antara kata-kata (words) dan dunianya (the world). ${ }^{4}$ Sedangkan semantik Alquran adalah kajian analitis terhadap istilah-istilah kunci hingga mencapai titik konseptual bagaimana masyarakat Arab era pewahyuan memahami Alquran. ${ }^{5}$ Menurut Toshihiko Izutsu, untuk memahami makna kata dalam Alquran diperlukan beberapa langkah analisis. Pertama, analisis makna dasar dan makna relasional. Makna dasar adalah makna yang terkandung dalam kata itu sendiri. Makna ini biasanya disebut dengan makna asli sebuah kata. Sedangkan makna relasional adalah makna baru yang diberikan pada sebuah kata dalam kasus tertentu dan atau dalam bidang tertentu. ${ }^{6}$

Oleh karena itu, dalam menganalisis makna relasional, para peneliti diharuskan untuk memperhatikan relasi sebuah kata dengan kata lainnya. Selain itu, untuk menemukan makna relasional diperlukan analisis sintakmatik dan paradigmatik. Analisis sintakmatik adalah analisis yang mencoba menemukan makna sebuah kata ketika kata tersebut berdampingan dengan kata yang lain. Analisis ini memerlukan perhatian terhadap kata sebelum dan sesudah kata yang diteliti dalam sebuah kalimat atau dalam sebuah plot. Dalam analisis sintakmatik, penulis menggunakan dua langkah analisis. Pertama, analisis berdasarkan bentuk lafaznya. Kedua, analisis berdasarkan keterkaitannya dengan lafaz lain. Untuk langkah kedua, penulis sajikan dalam aspek sinkronik lafaz khalasa era pewahyuan. Analisis paradigmatik adalah analisis terhadap sebuah kata dari segi antomin maupun sinonimnya, atau kata yang memiliki makna yang sepadan dan kata yang memiliki makna bertentangan.

Kedua, analisis sinkronik dan diakronik. Analisis sinkronik merupakan analisis untuk menemukan kata yang tidak berubah maknanya. Sedangkan analisis diakronik merupakan analisis untuk menemukan kata yang berubah dari beberapa kronologi waktu. Dalam kasus Alquran, Toshihiko Izutsu membagi

\footnotetext{
${ }^{4}$ Steen Gros, "Externalism in Semantics," in The Routledge Handbook of Semantics, ed. Nick Riemer (New York: Routlegde, 2016), 13.

5 Toshihiko Izutsu, Relasi Tuhan Dan Manusia: Pendekatan Semantik Terhadap Alquran (Yogyakarta: Tiara Wacana, 2003), 3.

${ }^{6}$ Ibid., 12.

7 Ibid., 16-29.
} 
kronologi waktu menjadi tiga bagian, pra-Quranik, era Quranik, dan postQuranik. ${ }^{8}$ Ketiga, menemukan weltanschaaung. Hal ini adalah langkah terakhir dalam teori semantik Izutsu. Weltanschaaung adalah pandangan masyarakat dalam memahami dan menggunakan kata-kata tersebut.

\section{Analisis Makna Dasar dan Relasional}

Makna dasar merupakan makna yang terkandung dalam kata itu sendiri. Meskipun kata tersebut digunakan dalam konteks kalimat yang berbeda tetapi memiliki kandungan makna yang tetap. Makna relasional yakni makna yang terkandung dalam sebuah konteks kalimat, atau makna yang dipengaruhi oleh struktur dan konteks tuturan (siyāq al-kalam) ${ }^{9}$ Oleh karena itu, untuk mendapatkan makna dasar dan makna relasional diperlukan studi analisis secara sintakmatik dan paradigmatik.

\section{Makna Dasar}

Kata Ikbläsh (إخلاص) berasal dari akblasa (أخَلَصن)-yukblisu-ikblashanmukblishin. Bentuk dasar dari akblasha (أَخلَصن) adalah khalasha (خَلَصن). Menurut Ibn Manżur dalam Lisān al-'Arab, makna kbalasha adalah sebuah keadaan yang melekat kemudian terlepas dan selamat. ${ }^{10}$ Ahmad bin Faris dalam Mu'jam Maqäyis al-Lugah mendefinisikan kata khalasha yakni membersihkan sesuatu dan memurnikannya. ${ }^{11}$ Dari sini dapat ditarik kesimpulan bahwa kata khalasha ini bermakna memurnikan.

\section{Makna Relasional}

Makna relasional merupakan makna yang muncul karena dipengaruhi oleh keadaan atau konteks kalimat. Oleh karena itu, dalam analisis ini memperhatikan struktur tuturan ayat menjadi penting. Derivasi lafaz khalasha (خلص) dalam Alquran terdapat 30 ayat yang tersebar dalam 17 surat. Derivasi tersebut berbentuk خلصو (khalashü) terdapat dalam QS. Yūsuf: 80. Lafaz أخلصوا (akblashnäbum) digunakan dalam QS. Shād [38]: 46. Lafaz أخلصناهم (akblashū) terdapat dalam QS. an-Nisā’ [4]: 146. Lafaz أستخلصه (astakblishbu) terdapat dalam QS. Yūsuf [12]:54. Lafaz الخالص (al-khälishu) terdapat dalam QS. al-Zumar [39]:3. Lafaz خالصا (khälishan) digunakan dalam QS. an-Naḥl [16]: 66. خالصة (kahälishatan) terdapat dalam QS. al-Baqarah [2]: 94, QS. al-An‘ām [6]: 139, QS. al-A'rāf [7]: 32, QS. al-Ahzāb: 50, QS. Shād [38]: 46. Lafaz

\footnotetext{
8 Ibid., 32-33.

${ }^{9}$ Ibid., 11.

${ }^{10}$ Ibnu Manzhur, Lisan Al-'Arab (Beirut: Dar al-Kutub al-Ilmiyah, 2009), 7, 29.

${ }^{11}$ Ahmad ibn Faris, Mu'jam Maqayis Al-Lughah (Beirut: Dar Ihya' Turats al-'Arabi, 2001),
} 309. 
مخلصون (mukblishan) terdapat dalam QS. az-Zumar: 2, 11, dan 14. Lafaz (mukblishinn terdapat dalam QS. al-Baqarah [2]: 139. Lafaz مخِصين (mukblishin) terdapat dalam QS. al-A'rāf: 29, QS. Yūnus [10]: 22, QS. al-'Ankabūt [29]: 65, QS. Luqmān [31]: 32, QS. Gāfir [40]: 14 dan 65, QS. al-Bayyinah [98]: 5. Lafaz مخلَصين مخَصًا (mukblashin) terdapat dalam QS. Yūsuf [12]: 24, QS. al- Hijr [15]: 40, QS. alȘāffāt [37]: 40, 74, 128, 160, 169, dan QS. Shād [38]: 83. ${ }^{12}$

\section{a. Analisis Sintakmatik}

\section{Derivasi khalasha yang berbentuk kata kerja (fic): أخلصوا , أخلصناهُم ,خَلصُوا,

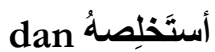

Derivasi khalasa yang berbentuk kata kerja terdapat dalam empat ayat dalam Alquran. Lafaz khalashī (خلصوا) terdapat dalam QS. Yūsuf [12]: 80. Lafaz akblashnābum (أخلصناهم) terdapat dalam QS. Shād [38]: 46. Lafaz akblashūu (أخلصو) terdapat dalam QS. an-Nisā' [4]: 146. Lafaz astakblishhu (أَنَنَخْلِكْنَ) terdapat dalam QS. Yūsuf [12]: 54. Berikut ayat-ayatnya:

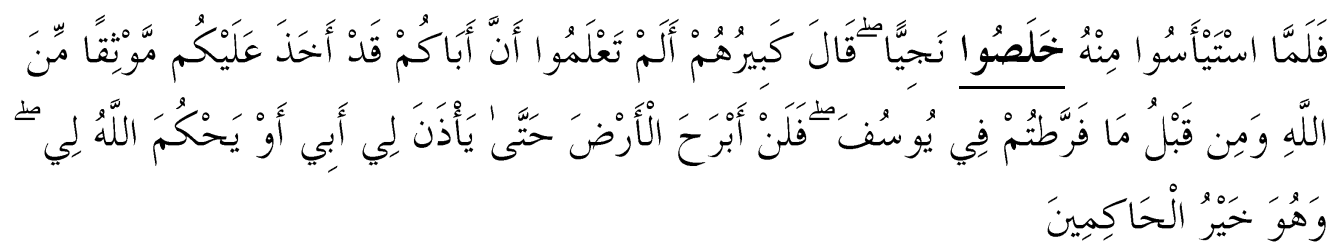

Maka tatkala mereka berputus asa dari pada (putusan) Yusuf mereka menyendiri sambil berunding dengan berbisik-bisik. Berkatalah yang tertua diantara mereka: "Tidakkah kamu ketabui bahwa sesunggubnya ayabmu telah mengambil janji dari kamu dengan nama Allab dan sebelum itu kamu telah menyia-nyiakan Yüsuf. Sebab itu aku tidak akan meninggalkan negeri Mesir, sampai ayabku mengizinkan kepadaku (untuk kembali), atau Allah memberi keputusan terbadapku. Dan Dia adalah hakim yang sebaik-baiknya". (QS. Yüsuf [12]: 80).

QS. Yūsuf [12]: 80 berbicara tentang kisah sebagian saudara Yūsuf yang sedang berunding mengenai siapa salah seorang dari mereka yang akan menjadi budak selama satu tahun sebagai hukuman. Dalam ayat ini, terdapat kata (khalashū). Menurut Ibn Manzhūr, kata khalashū bermakna تَمَيَزُوا عن الناس yakni membedakan diri dari manusia atau menyendiri dari sebuah kaum. ${ }^{13}$ Kata khalashü tersebut merupakan kata kerja (fíl madhi) yang menyatakan bahwa

\footnotetext{
12 Muhammad Fuad Abdul Baqî, Al-Mu'jam Al-Mufahras Li Alfaz̧h Al-Quran Al-Karim Bi Hasyiah Al-Mushaf Al-Syarifah (Kairo: Dar al-Hadis, 2001), 292.

${ }^{13}$ Manzhur, Lisan Al-'Arab, 30.
} 
saudara Yūsuf telah berbuat sesuatu, yakni menyendiri (kata kerja). Kata selanjutnya adalah najjyyan (نَيَّ) yang menjadi hăl atau menjelaskan keadaan yang memisah lagi cemas. Jadi, makna khalashū di sini bermakna memisah atau berbeda.

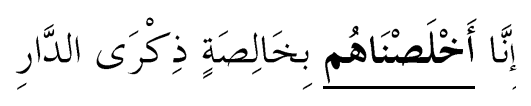

Sesunggubnya Kami telah menyucikan mereka dengan (menganugerahkan kepada mereka) akblak yang tinggi yaitu selalu mengingatkan (manusia) kepada negeri akbirat. (QS. Șäd [38]: 46)

Ibn Manzhūr dalam Lisān al-'Arab menyatakan bahwa maksud dari akblashnāhum (أَخَصَنَاهُم) adalah menjadikan mereka sebagai orang yang khälish (خالص). Kata khälish di sini bermakna orang yang mengesakan. ${ }^{14}$ Ayat ini menjelaskan bahwa Allah telah mengesakan mereka (أخلَصنَاهم). Mereka maksudnya ialah -mengacu kepada 5 ayat sebelumnya -QS. Șād: 41-45- yakni Nabi Ayyūb, Ibrāhīm, Ishāq, dan Ya'qūb. Jadi, mengesakan di sini memakai kata kerja akblashnā. Allah sebagai fä́li-nya dan nabi-nabi tersebut menjadi maf'ül-nya.

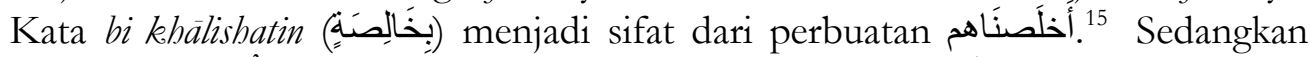

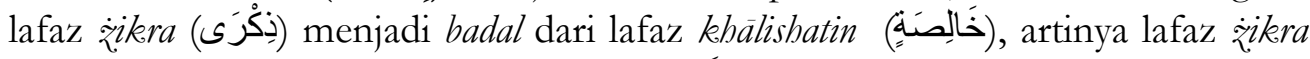

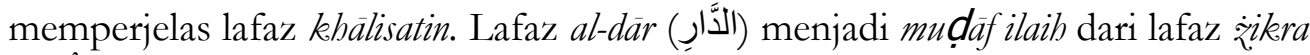

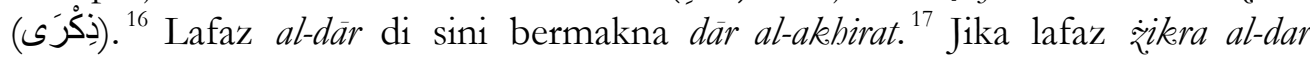
memperjelas lafaz khälisatin, maka salah satu konsep dari mengesakan Allah adalah ingat kepada kehidupan akhirat. Selanjutnya makna lafaz akblashü dalam QS. an-Nisā' [4]: 146,

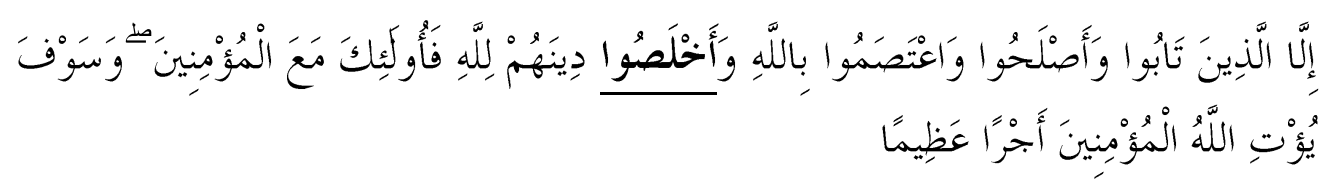

Kecuali orang-orang yang taubat dan mengadakan perbaikan dan berpegang teguh pada (agama) Allah dan tulus ikblas (mengerjakan) agama mereka karena Allah. Maka mereka itu adalah bersama-sama orang yang beriman dan kelak. Allah akan memberikan kepada orang-orang yang beriman pabala yang besar. (QS. an-Nisä' [4]: 146)

${ }^{14}$ Ibn Manzhur menjelaskan bahwa lafaz المخلص bermakna الذي وحد اله تعالى خالصًا . Oleh karena itu, menurut penulis lafaz khaliṣan bermakna "mengesakan". Lihat Ibid., 29-30.

${ }^{15}$ Muhy al-Din al-Darwisy, I'rab Al-Qur'an Al-Karim Wa Bayanub (Beirut: Dar Ibn Kasir, 1999), 6, 472.

${ }^{16}$ Bajat 'Abd al-Wahid Shalih, Al-I'rab Al-Mufashshal Li Kitab Allah Al-Murrattal (Beirut: Dar al-Fikr, n.d.), 117.

${ }^{17}$ Muhammad bin 'Abdullah al-Husaini al-Alusi, Rub Al-Ma'ani Fi Tafsir Al-Qur'an Al'Az̧him (Beirut: Dar Ihya' Turats al-'Arabi, 1985), 7, 399. 
QS. an-Nisā' [38]: 146 berbicara tentang orang-orang yang bertaubat. Sebagaimana dalam ayat sebelumnya (baca: QS. an-Nisāa [4]: 145) yang menjelaskan keadaan orang-orang munafik yang tidak akan tertolong dan kekal dalam neraka. QS. an-Nisā̄' [4]: 146 menjadi pengecualian dengan syarat-syarat

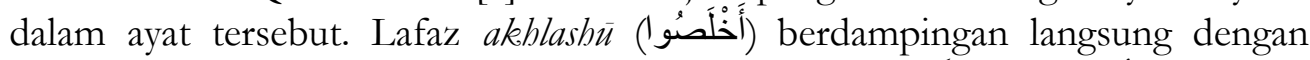
lafaz al-din dan Alläh. Menurut Ibn Manzhūr, kalimat أخلص الله دينَه bermakna

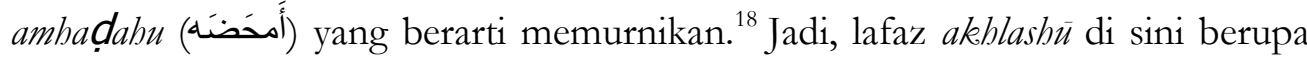
perintah untuk memurnikan ajaran agama.

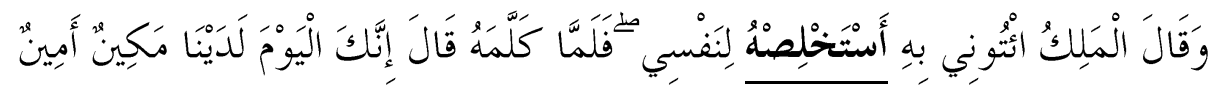

Dan raja berkata: "bawalah Yusuf kepadaKu, agar aku memilih dia sebagai orang yang rapat kepadaku". Maka tatkala raja telah bercakap-cakap dengan dia, dia berkata: "Sesunggubnya kamu (mulai) bari ini menjadi seorang yang berkedudukan tinggi lagi dipercayai pada sisi kami". (QS. Yüsuf [12]: 54)

QS. Yūsuf [12]: 54 berbicara tentang kejujuran Yūsuf yang pada akhirnya mendapat kepercayaan dari seorang raja. Lafaz astakblishbu (أَسْنَخْلِصنْفُ) di sini bermakna istakhashshahu (اسنَخَصَّنَ) yang berarti minta bergabung. ${ }^{19}$ Lafaz

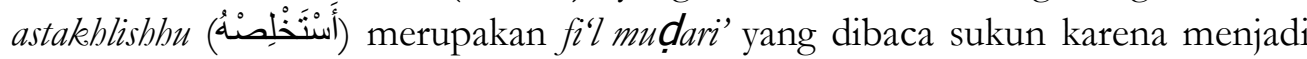
jawab dari amr. Raja meminta Yūsuf untuk bergabung dengannya. Jadi, lafaz astakblishbu di sini berarti berpisah dari yang lain dan minta bergabung kepada yang lain. Hal ini juga dijelaskan oleh Ibn Manzhūr menggunakan ungkapan

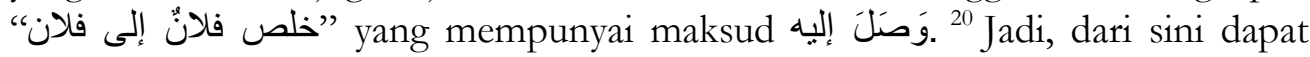
disimpulkan bahwa pengunaan kata astakblishbu, dalam konteks raja dan Yūsuf, bermakna bergabung.

\section{Derivasi khalasha yang berbentuk ism: مخلصون ,مخلصنًا ,خَالِصة ,خَلِصًا, الخَالِصِ , مخلصِين dan مخلصًا ,مخلصِين}

Untuk mempermudah kajian, penulis menggolongkan lafaz-lafaz

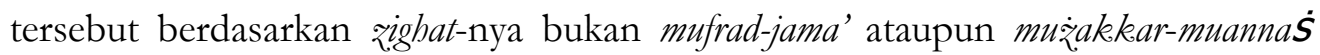
nya, karena mempertimbangkan tujuan bab ini, yakni mencari integrasi antar

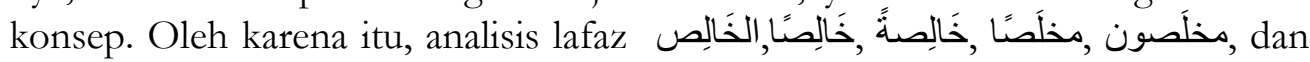
dijadikan dalam satu bahasan karena sama-sama ism fä́ril. Sedangkan Lafaz ملخَلَصين dan dijadikan satu bahasan karena keduanya sama-sama ism maf'ül.

${ }^{18}$ Manzhur, Lisan Al-'Arab, 7, 29.

19 Al-Fairuz Zabadi Muhammad ibn Ya'qub, Qamus Al-Mubith (Beirut: Muassasah alRisalah, 1993), 2, 162.

${ }^{20}$ Manzhur, Lisan Al-'Arab, 7, 30. 


\section{Derivasi khalasha yang berupa ism fācil: Analisis Lafaz خَالِصنًا, الخَالِصن, dan خَالِصنَة}

Lafaz الخَالِصن (al-khālishu) terdapat dalam QS. az-Zumar [39]: 3. Lafaz خَالِصَنً (khālishatan) terdapat dalam Q.S. al-Baqarah [2]: 94, al-An'ām [6]: 139, al-A'rāf [7]: 32, al-Ahzāb [33]: 50, QS. Shād [38]: 46. ${ }^{21}$ Berikut redaksi lengkap dan analisis ayat-ayatnya:

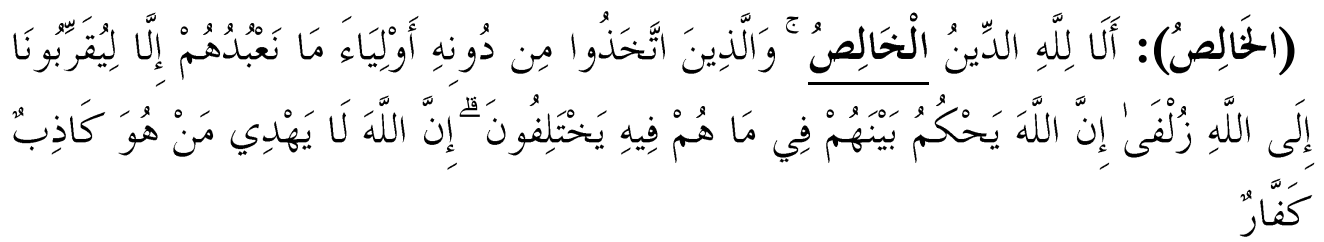

Ingatlah, hanya kepunyaan Allah-lah agama yang bersib (dari syirik). dan orang-orang yang mengambil pelindung selain Allah (berkata): "Kami tidak menyembah mereka melainkan supaya mereka mendekatkean Kami kepada Allah dengan sedekat-dekatnya". Sesunggubnya Allah akan memutuskan di antara mereka tentang apa yang mereka berselisib padanya. Sesungguhnya Allah tidak menunjuki orang-orang yang pendusta dan sangat ingkar (QS. az-Zumar [39]: 3)

QS. az-Zumar [39]: 3 menjelaskan tentang agama. Lafaz al-khälishu

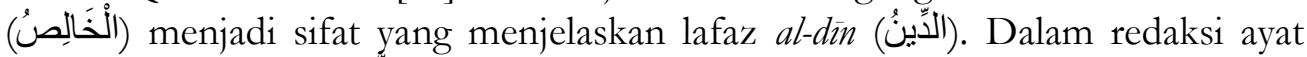
tersebut, lafaz Allāh (لِّ) menjadi khabar muqaddam (khabar yang didahulukan), sedangkan al-din (الدِّنُ) menjadi mubtada' mu'akhkhar (mubtada yang diakhirkan). ${ }^{22}$ Dalam kaidah bahasa Arab, apabila ada khabar yang terbentuk dari jar-majrür, maka khabar tersebut menyimpan makna "tetap". Jadi dalam hal ini, lafaz alkhālishu menjelaskan ketetapan karakteristik agama Allah.

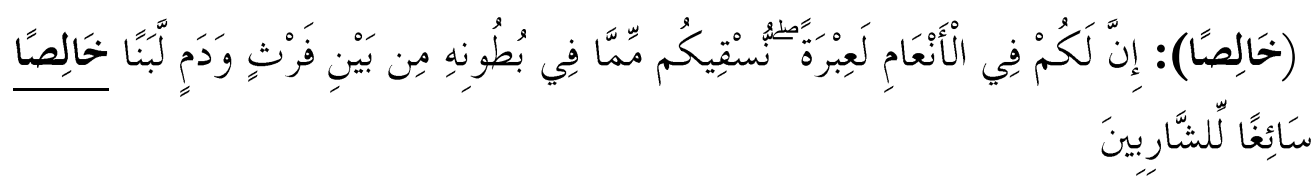

Dan Sesunggubnya pada binatang ternak itu benar-benar terdapat pelajaran bagi kamu. Kami memberimu minum dari pada apa yang berada dalam perutnya (berupa) susu yang bersih antara tabi dan darah, yang mudah ditelan bagi orang-orang yang meminumnya. (QS. an-Nabl: 66)

${ }^{21}$ Untuk QS. Shad [38]: 46 sudah penulis jelaskan di bagian $\mathrm{fi}^{\prime} \mathrm{l}$

22 al-Darwisy, I'rab Al-Qur'an Al-Karim Wa Bayanuh, 6, 488. 


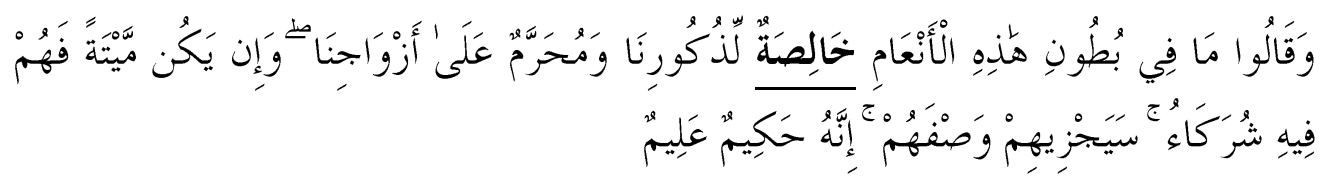

Dan mereka mengatakan: "Apa yang ada dalam perut binatang ternak ini adalah kbusus untuk pria Kami dan diharamkan atas wanita kami," dan jika yang dalam perut itu dilabirkan mati, Maka pria dan wanita sama-sama boleh memakannya. kelak. Allah akan membalas mereka terhadap ketetapan mereka. Sesunggubnya Allab Maba Bijaksana lagi Maha Mengetahui. (QS. al-An'äm: 139)

Dua ayat di atas (QS. an-Nahl [16]: 66 dan QS. al-An'ām [6]: 139) menjelaskan tentang binatang ternak. Lafaz khālishan dalam QS. an-Nahl [16]: 66

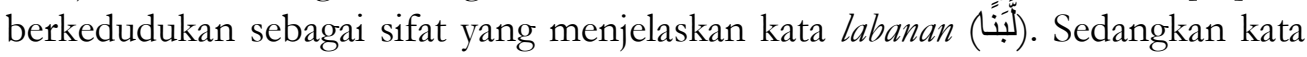
khälishatun dalam QS. al-An'am [6]: 139 berkedudukan sebagai khabar dari kata Ĺ. Sebagaimana disebutkan oleh Ibn Manzhūr bahwa derivasi khalasha yang berhubungan dengan benda maka bermakna bersih. ${ }^{23}$

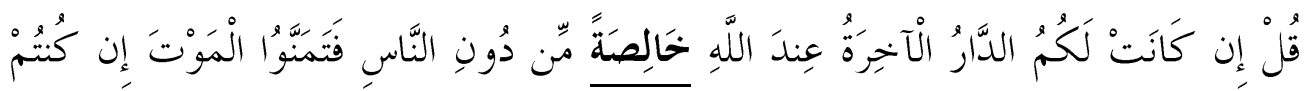
صَادِقِنْ

Katakanlah: "Jika kamu (menganggap bahwa) kampung akbirat (surga) itu khusus untuk.mu di sisi Allah, bukan untuk orang lain, maka inginilah kematian (mu), jika kamu memang benar. (QS. al-Baqarah [2]: 94)

Dalam QS. al-Baqarah [2]: 94, lafaz الأَّارُ الْآخِرَةُ (al-dār al-akhirah) berhubungan dengan lafaz khālishatan (خَالِصنَ). Lafaz al-dār al-akhirah menjadi ism-nya كَانَتْ. Sedangkan khālishatan (خَالِْنَ) menjadi hāl. Menurut Ibn Manzhūr, lafaz khälishatan (خَالِصَنَ) dalam konteks ini bermakna khāshshah (خَاصَّ) yang berarti "khusus". ${ }^{24}$ Makna seperti ini juga terdapat dalam QS. al-Ahzāb [33]: $50 .^{25}$

${ }^{23}$ Manzhur, Lisan Al-'Arab, 7, 29.

24 Ibid., 7, 30.

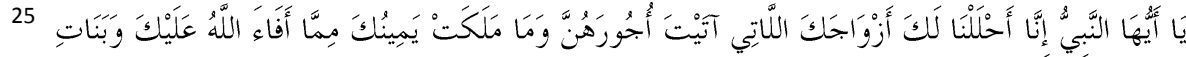

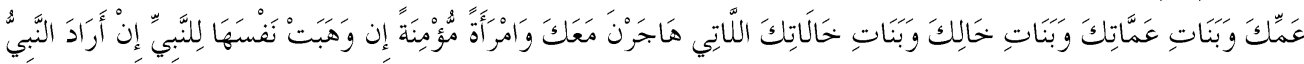

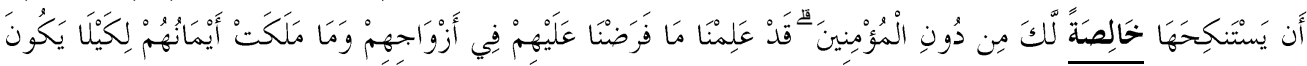

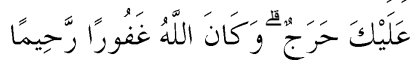




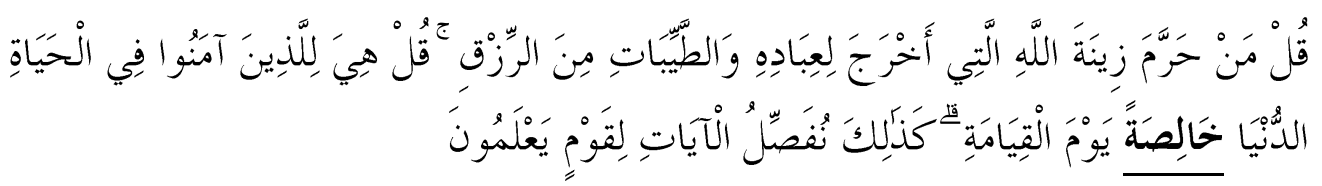

Katakanlah: "Siapakah yang mengharamkan perbiasan dari Allah yang telah dikeluarkanNya untuk hamba-bamba-Nya dan (siapa pulakah yang mengharamkan) rezki yang baik?" Katakanlah: "Semuanya itu (disediakan) bagi orang-orang yang beriman dalam kehidupan dunia, khusus (untuk mereka saja) di hari kiamat." Demikianlah Kami menjelaskan ayat-ayat itu bagi orang-orang yang mengetabui. (QS. al-A'räf: 32)

Term yaum al-qiyāmah (يَ) الْوَمَ) dalam QS. al-A'rāf [7]: 32 menjadi Zharaf yang berhubungan dengan kata khälishatan (خَالِّفَ). Lafaz khälishatan merupakan hāl yang menjelaskan term زيَنَ اللَّهِ. Jadi, di sini dijelaskan bahwa perhiasan dari Allah diberikan khusus kepada orang-orang yang beriman di dunia dan di hari kiamat.

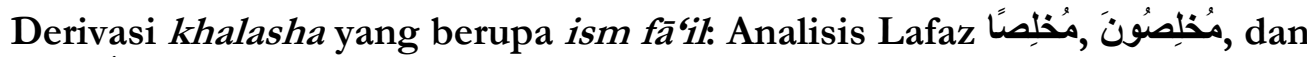 مُخِلصِينَ}

Lafaz مخلصًا (mukhlishan) terdapat dalam QS. al-Zumar [39]: 2, 11, dan 14. Lafaz مخلصون (mukblishīn) terdapat dalam QS. al-Baqarah [2]: 139. Lafaz مخلِصين (mukhlishin) terdapat dalam QS. al-A'rāf [7]: 29, QS. Yūnus [10]: 22, QS. al-Ankabūt [29]: 65, QS. Luqmān [31]: 32, QS. Gāfir [40]: 14, 65, dan QS. alBayyinah [98]: 5, berikut ayat-ayat dan analisisnya:

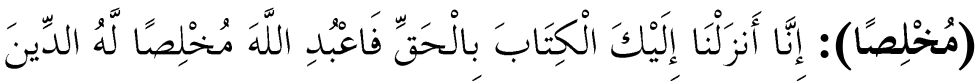

Sesunguhnya Kami menurunkan kepadamu kitab (Alquran) dengan (membawa) kebenaran. Maka sembahlah Allab dengan memurnikan ketaatan kepada-Nya. (QS. ar-Zumar: 2)

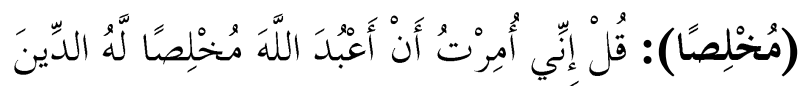

Katakanlah: "Sesunggubnya aku diperintabkan supaya menyembah Allab dengan memurnikan ketaatan kepada-Nya dalam (menjalankan) agama. (QS. az-Zumar: 11)

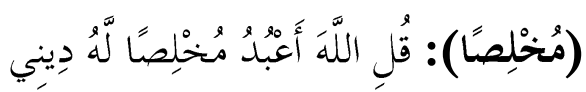

Katakanlah: "Hanya Allah saja yang aku sembah dengan memurnikan ketaatan kepadaNya dalam (menjalankan) agamaku". (QS. az-Zumar: 14)

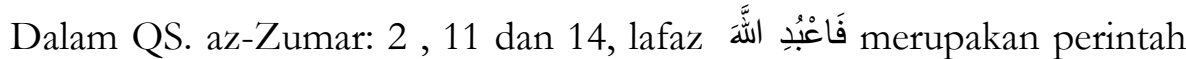
untuk menyembah Allah. Lafaz mukhlishan (مُخْلِصنًا) berkedudukan sebagai hāl, yakni sebagai penjelas maksud terhadap penyembahan tersebut. Dalam konteks 


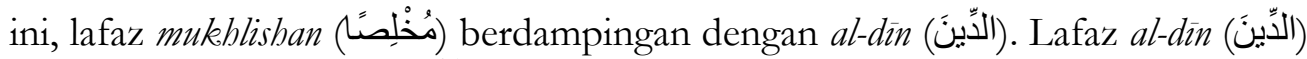
menjadi objek (maf'ül bih) ${ }^{26}$ Persamaan antar ketiga ayat tersebut, yakni samasama berbentuk perintah dan struktur kalimatnya. Jadi, Allah memerintah kepada hambanya untuk menyembah-Nya dengan cara menauhidkan agama.

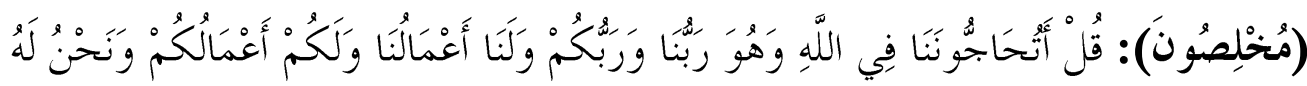

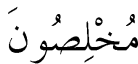

Katakanlab: "Apakah kamu memperdebatkan dengan Kami tentang Allah, Padabal Dia adalah Tuban Kami dan Tuban Kamu; bagi Kami amalan Kami, dan bagi kamu amalan kamu dan hanya kepada-Nya Kami mengikblaskan bati (QS. al-Baqarah [2]: 139)

QS. al-Baqarah [2]: 139 menjelaskan tentang amal (perbuatan) orang mukmin dan penganut agama Yahudi dan Nasrani (QS. al-Baqarah [2]: 135-138). Lafaz mukblishōn (مُخْلِصُونَ) menjadi khabar dari lafaz nanbu (نَخْنَ). ${ }^{27}$ Jadi, amal (perbuatan) orang-orang mukmin yaitu memurnikan agama Allah.

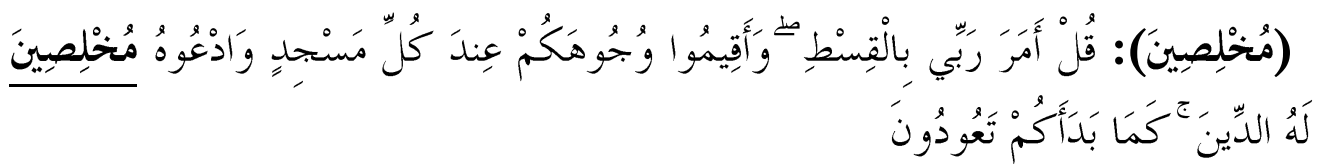

Katakanlah: "Tubanku menyurub menjalankan keadilan". dan (katakanlab): "Luruskanlah muka (diri) mu di Setiap sembahyang dan sembablah Allab dengan mengikblaskan ketaatanmu kepada-Nya. Sebagaimana Dia telah menciptakan kamu pada permulaan (demikian pulalah kamu akan kembali kepada-Nya)". (QS. al-A'räf: 29).

QS. al-A'rāf [7]: 29 di atas menjelaskan tentang perintah Allah yang harus dilaksanakan oleh segenap umat di bumi. Lafaz mukblishin (مُخْلِصِينَ) di sini sebagai häl dan lafaz al-din (الدَّين) sebagai maf'ül atau objeknya. ${ }^{28}$ Kasus struktur lafaz mukblishin (مُخْلِصِين) seperti ini juga terdapat dalam QS. Yūnus [10]: 22,

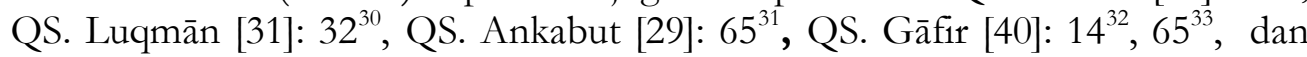

\footnotetext{
26 al-Darwisy, I'rab Al-Qur'an Al-Karim Wa Bayanuh, 6, 488.

${ }^{27}$ Ibid., 1, 182.

${ }^{28}$ Ibid., 2, 541.

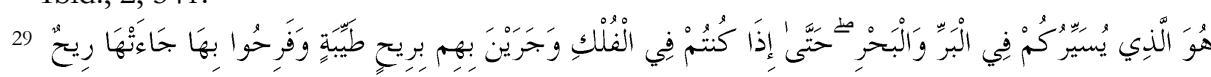

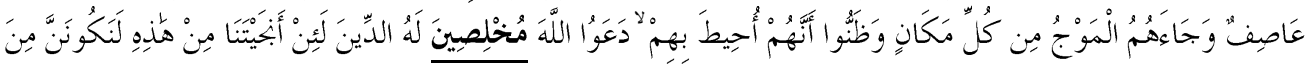
الشَّاَكرينَ

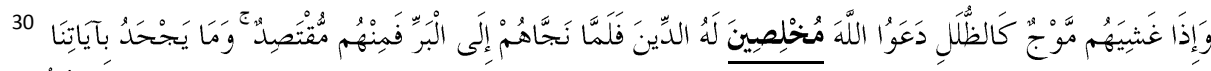

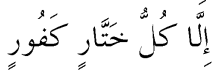


QS. al-Bayyinah: $5^{34}$. Lafaz mukblishin (مُخْلِيحِينَ) merupakan bentuk jamak dari mukblish (مُخْلِص). Menurut Ibn Manẓūr, lafaz mukblish (مُخْلِصنَ) ketika berhubungan dengan kata al-din bermaknal الذي وحّد اله تعالى خالصًا yang berarti "orang yang menauhidkan Allah". 35

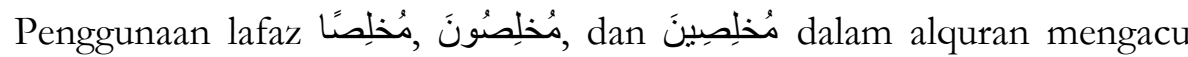
kepada sistem ketuhanan dalam Islam. Allah memeritahkan kepada seluruh hambanya agar menyembah kepada-Nya dengan mengesakan agama, melalui lafaz-lafaz tersebut. Termasuk dalam amal-amal (QS. al-Baqarah [2]: 139) keseharian umat mukmin diperintah agar tidak menyekutukan-Nya.

\section{Derivasi khalasha yang berupa ism maf ${ }^{\natural} \bar{u} 1$}

Derivasi khalasha yang berupa ism maf'ül yakni mukblashan (مخَلَصًا) terdapat dalam QS. Maryam [19]: 51, ملخََصين (mukblashin) terdapat dalam QS. Yūsuf [12]: 24, QS al-Hijr [15]: 40, QS. al-Shāffāt [12]: 40, 74, 128, 160, 169, dan QS. Shād: 83. Berikut ayat dan penjelasannya:

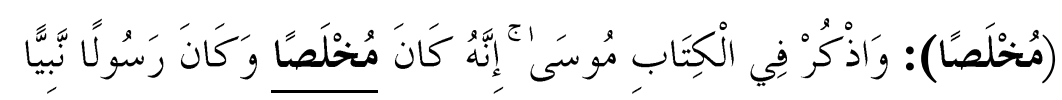

Dan ceritakanlah (hai Muhammad kepada mereka), kisah Musa di dalam Al kitab (Alquran) ini. Sesunggubnya ia adalah seorang yang dipilih dan seorang Rasul dan Nabi. (QS. Maryam [19]: 51)

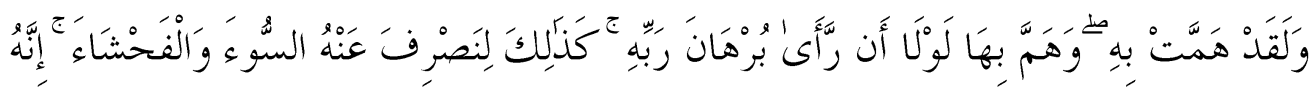

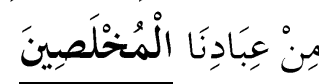

Sesunggubnya wanita itu telah bermaksud (melakukan perbuatan itu) dengan Yusuf, dan Yusufpun bermaksud (melakukan pula) dengan wanita itu andaikata Dia tidak melihat tanda (dari) Tuhannya. Demikianlah, agar Kami memalingkan dari padanya kemungkaran dan kekejian. Sesunggubnya Yusuf itu termasuk hamba-bamba Kami yang terpilib. (QS. Yüsuf [12]: 24)

Lafaz mukblashan (مُخََْسًا) dalam QS. Maryam [19]: 51 berkedudukan sebagai khabar yang menjelaskan keadaan Nabi Musa. Menurut Ibn Manzhūr lafaz mukblashan (مُخْلَصًا) mempunyai makna الذي أخلصه الله جعله مختارًا خالصًا من

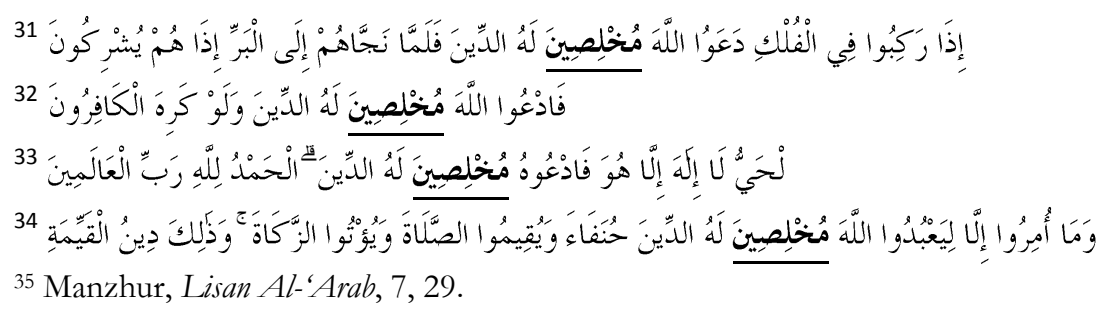


الدنس yang berarti "orang yang dibersihkan oleh Allah, menjadikannya terpilih dan bersih dari dosa". Begitu juga pada kisah Nabi Yūsuf dalam QS. Yusuf [12]: 24. Jadi, lafaz mukblashan (مُخْلَصًا) di sini bermakna terpilih, siapa yang memilih? Allah yang memilih. Siapa yang dipilih? Hal ini berhubungan dengan QS. al-Hijr [15]: $40^{36}$, QS. al-Shāffāt: 40, 74, 128, dan $160^{37}, 169^{38}$.

Makna relasional kata khalasha (خلص) bisa berupa bersih, memisahkan, khusus, dan menauhidkan. Sedangkan secara penggunaan konteks kalimat (siyaq), derivasi khalasha dalam Alquran terdapat dua bentuk konsep besar. Pertama, penggunaannya pada konsep agama (al-din). Kedua, konsep terhadap benda yang berarti bersih. Dari analisis sintakmatik, derivasi khalasha dalam Alquran berhubungan dengan beberapa konsep lain. Berikut tabel keterangan derivasi khalasha dan hubungannya dengan lafaz lain.

Tabel 1: Deriavsi Khalasha dan Kaitannya dengan Lafaz Lain

\begin{tabular}{|c|c|c|c|}
\hline No & $\begin{array}{c}\text { Derivasi Khalasha dan } \\
\text { Keterkaitannya }\end{array}$ & Jumlah & Rincian \\
\hline 1. & $\begin{array}{l}\text { Derivasi khalasha dan } \\
\text { hubungannya dengan kata al- } \\
\text { dar dan yaum al-qiyamah }\end{array}$ & 3 ayat & $\begin{array}{l}\text { QS. Shād [38]: } 46 \\
\text { QS. al-Baqaah [2]: } 94 \\
\text { QS. al-A'rāf [7]: } 32\end{array}$ \\
\hline 2. & $\begin{array}{l}\text { Derivasi khalasha dan } \\
\text { hubungannya dengan Nabi } \\
\text { dan Rasul }\end{array}$ & 2 ayat & $\begin{array}{l}\text { QS. Maryam [19]: } 51 \\
\text { QS. al-Ahzāb [33]: } 50\end{array}$ \\
\hline 3. & $\begin{array}{l}\text { Derivasi khalasha dan } \\
\text { hubungannya dengan al-din } \\
\text { (agama) }\end{array}$ & 12 ayat & $\begin{array}{l}\text { QS. an-Nisā' [4]: } 146 \\
\text { QS. az-Zumar [39]: } \\
\text { 2,3,11, dan 14 } \\
\text { QS. al-A'rāf [7]: } 29 \\
\text { QS. Yūnus [10]: } 22 \\
\text { QS. al-Ankabūt [29]: } 65 \\
\text { QS. Luqmān [31]: } 32 \\
\text { QS. Gāfir [40]: 14, } 65 \\
\text { QS. al-Bayyinah [98]: } 5\end{array}$ \\
\hline 4. & $\begin{array}{l}\text { Derivasi khalasha dan } \\
\text { hubungannya dengan al-'abd } \\
\text { (hamba) }\end{array}$ & 8 ayat & $\begin{array}{l}\text { QS. Yūsuf [12]: } 24 \\
\text { QS. al-Hijr [15]: } 40 \\
\text { QS. al-Shāffāt [37]: 40, } \\
74,127,160 \text {, dan } 169\end{array}$ \\
\hline
\end{tabular}

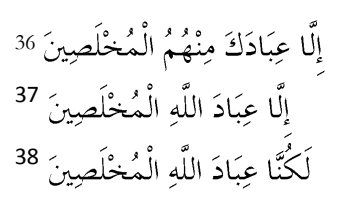




\begin{tabular}{|c|c|c|c|}
\hline & & & QS. Shād [38]: 83 \\
\hline 5. & $\begin{array}{l}\text { Derivasi khalasha dan } \\
\text { hubungannya dengan kata al- } \\
\text { Amal (perbuatan) }\end{array}$ & 1 ayat & QS. al-Baqarah [2]: 139 \\
\hline 6. & $\begin{array}{l}\text { Derivasi khalasha dan } \\
\text { hubungannya dengan kisah } \\
\text { Yusuf }\end{array}$ & 2 ayat & $\begin{array}{l}\text { QS. Yūsuf [12]: } 80 \\
\text { QS. Yūsuf [12]: } 54\end{array}$ \\
\hline 7. & $\begin{array}{l}\text { Derivasi khalasha dan } \\
\text { hubungannya dengan term } \\
\text { laban (susu) }\end{array}$ & 1 ayat & QS. an-Nahl [16]: 66 \\
\hline \multirow[t]{2}{*}{8.} & $\begin{array}{l}\text { Derivasi khalasha dan } \\
\text { hubungannya dengan al- } \\
\text { An'àm (binatang ternak) }\end{array}$ & 1 ayat & QS. al-An‘ām [6]: 139 \\
\hline & Total & 30 ayat & \\
\hline
\end{tabular}

\section{b. Kajian Paradigmatik}

Analasis sintakmatik membuktikan bahwa kata khalasha dan derivasinya dalam Aquran digunakan dalam dua bentuk, yakni dalam hal benda dan agama. Penggunaan derivasi kbalasha dalam konteks agama, berarti mennauhidkan agama. Oleh karena itu, antonim ialah syirik. ${ }^{39}$ Syirik berasal dari bahasa Arab. Kata syirik berasal dari madhi شَرَكَ (syarika-yasyriku-syarkan-syirkatan-syarikatan). Ahmad bin Faris dalam Mäqäyìs al-Lughah menjelaskan bahwa kata syin-ra'-kaf salah satunya digunakan untuk menujuk pembedaan, beroposisi dari salah satu yang lain. ${ }^{40}$ Menurut Ibn Manzūr, kata al-syirk dalam QS. Luqman [31]: 13 bermakna ان تجعل له شريكًا في ربوبيته yang berarti menyekutukan Allah. ${ }^{42}$

Jika dikaitkan dengan kata ikhlas, sangat jelas bahwa Allah -dengan menggunakan term khalasha dalam Alquran memerintahkan kepada umat manusia untuk menyembah Dia saja, tanpa ada kata "menduakan Allah". Hal ini sangat jelas jika dilihat dari sudut pandang term syirik dalam Alquran yang bermakna berserikat dengan yang lain. Oleh karena itu, berserikat dalam hal ketuhanan tidak pernah dibenarkan oleh Allah. Kata ikblash dalam Alquran hanya muncul satu kali yakni dalam nama surat yang ke 112. Menurut Ibn Manzhūr kata ikhlash bermakna kalimat tauhid (baca: mengesakan Allah). ${ }^{43}$

${ }^{39}$ Penentuan syirik sebagai suatu yang bersebrangan dengan khalasha disinggung dalam QS. al-Ankabūt: 65 dan QS. al-Gāfir: 14.

40 ibn Faris, Mu'jam Maqayis Al-Lughah, 535.

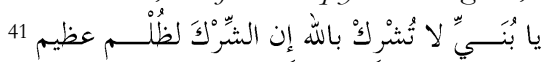

42 Manzhur, Lisan Al-'Arab, 5. 534.

${ }^{43}$ Ibid., 7, 29. 


\section{Analisis Sinkronik dan Diakronik}

Bagian ini mendiskusikan tentang perkembangan makna. Aspek sinkronik adalah konsep yang statis pada sebuah masa. sedangkan aspek diakronik adalah tinjauan terhadap konsep dari segi waktu ke waktu. ${ }^{44}$ Sub bab ini menjelaskan bagaimana kata khalasha dan derivasinya dimaknai dalam waktu sebelum Alquran turun, era pewahyuan Alquran, dan bagaimana kata tersebut dimaknai dalam kurun waktu setelah Alquran turun.

\section{Pra Quranik}

Untuk melacak makna khalasha dan derivasinya pra Alquran, perlu melacaknya dalam syair-syair Arab yang berkembang sebelum Alquran diturunkan. Term الخَلَصن dalam syair Arab pra Islam mempunyai berbagai makna. Pertama, digunakan untuk menyebut nama pohon. Kedua, term ini juga untuk menyebut pakaian orang-orang Syam. Baju pakaian orang-orang Syam yang diperindah dengan warna bahu hijau, lengan dan bawahan yang berwarna putih. Ketiga, dikatakan juga bahwa setiap sesuatu yang putih itu bermakna

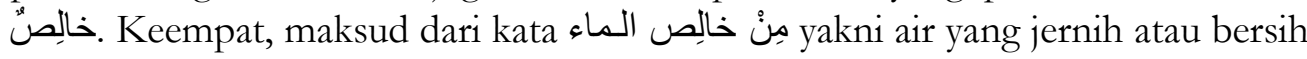
tanpa lumut.

Kelima, dikatakan oleh al-Laiś, bahwa unta mukblish dalam syair Arab ditujukan untuk menyebut unta yang gemuk. Keenam, lafaz al-khälish bermakna bersih kosong dari warna, seperti dalam frasa tsawb khälish (نوب خالص) bermakna baju putih dan ma' khälish (ماء خالص) bermakna air putih atau jernih. Ketujuh, kata al-khalsha'u (الخَلْصَاءُ) juga dipakai untuk menunjukkan air di padang pasir atau gurun, namun ada juga yang mengatakan nama tempat mata air. ${ }^{45}$ Jadi, dari sini dapat ditarik 'benang merah' bahwa penggunaan kata kbalasha dan derivasinya dalam tradisi pra Arab merujuk terhadap suatu konsep yang mengagumkan dan suci, seperti air jernih, baju yang indah, dan unta yang gemuk.

\section{Quranik; Era Pewahyuan}

Penggunaan lafaz khalasha dan derivasinya dalam Alquran mengacu terhadap dua konsep penggunaan. Pertama, lafaz khalasha dan derivasinya dalam Alquran digunakan mayoritas untuk menjelaskan konsep agama. Kedua, lafaz khalasha dan derivasinya dalam Alquran untuk menjelaskan sebuah benda. Lebih jelasnya, penggunaan lafaz khalasha dan derivasinya dalam Alquran berhubungan langsung dengan agama (al-dīn), hari akhir (där al-akbirab), hari akhir (yawm al-

\footnotetext{
${ }^{44}$ Izutsu, Relasi Tuhan Dan Manusia, 32-33.

${ }^{45}$ Manzhur, Lisan Al'A Arab, 7, 31-32.
} 
qiyamab), hamba ('abd), para nabi dan utusan (risälab), dan berkaitan dengan benda; susu dan binatang ternak (al-laban wa al-an'am).

Derivasi lafaz khalasha yang berbentuk kata kerja (fi'l) terdapat dalam 4 ayat Alquran. Dari 4 ayat tersebut, dua di antaranya berhubungan langsung dengan agama (QS. Shād [38]: 46 dan an-Nisā'] [4]: 146). Sedangkan dua lainnya berhubungan dengan kisah memisahnya saudara-saudara Nabi Yūsuf dari sebuah kaum dan berhubungan dengan kisah bergabungnya Nabi Yūsuf kepada seorang raja (QS. Yūsuf [12]: 80 dan 54).

Derivasi lafaz khalasha yang berbentuk kata benda (ism) terdapat dalam 27 ayat Alquran. Derivasi lafaz khalasha yang berbentuk ism dalam Alquran terbagi menjadi dua, ism fäl dan ism maf'ül. Derivasi lafaz khalasha yang berbentuk ism fä́il terdapat dalam 18 ayat. Ayat-ayat tersebut membahas beberapa tema di antaranya ialah, pertama, berkaitan dengan pemurnian menauhidkan - agama (13 ayat). ${ }^{46}$ Kedua, berkaitan dengan hari akhir atau kiamat (3 ayat). ${ }^{47}$ Ketiga, berkaitan dengan kemurnian sebuah benda ( 2 ayat). ${ }^{48}$ Sedangkan derivasi lafaz khalasha yang berbentuk ism maf'ül terdapat dalam 9 ayat. Keseluruhan ayat tersebut membahas tentang orang-orang yang disucikan oleh Allah. ${ }^{49}$ Oleh karena itu, derivasi lafaz khalasha dalam Alquran mayoritas digunakan untuk menjelaskan agama (al-din) dan yang berkaitan dengannya, seperti hari kiamat, para nabi, alam akhirat, dan amal perbuatan.

Apabila dibandingkan dengan penggunaan term khalasha era sebelum Alquran, maka terdapat perbedaan yang sangat signifikan dalam konteks makna ikblash. Sebagaimana di atas telah dijelaskan bahwa di era pra Alquran lafaz khalasha dan derivasinya hanya untuk menjelaskan benda suci dan mengagumkan. Berbeda dengan itu, di era pewahyuan lafaz khalasha dan derivasinya mayoritas menjelaskan tentang agama. Oleh karena itu, dalam konteks pewahyuan, lafaz khalasha dan derivasinya mempunyai makna baru dan berbeda dengan makna di era pra pewahyuan.

Dalam konteks agama, lafaz khalasha dan derivasinya dalam Alquran digunakan untuk menjelaskan tentang konsep ajaran dalam agama dan Alquran sebagai kitab petunjuk memerintahkan kepada seluruh manusia ('abd) untuk memurnikan ajaran, menauhidkan agama, dan mengesakan Allah. Oleh karena itu, dalam konteks era pewahyuan, nama surat al-ikblash dalam surat ke-112 tidak

${ }^{46}$ QS. al-Zumar [39]:3, 2, 11, dan 14; QS. al-A'rāf [7]: 2 dan 32; QS. Șād [38]: 46; QS. alBaqarah [2]: 139; QS. Yūnus [10]: 22; QS. al-'Ankabūt [29]: 65; QS. Luqmān [31]: 32; QS. Gāfir [40]: 14 dan 65; dan QS. al-Bayyinah [98]: 5.

47 QS. al-Baqarah [2]: 94; QS. al-Aḥzāb [33]: 50, dan QS. al-A'rāf [7]: 32.

${ }^{48}$ QS. an-Nahl [16]: 66 dan QS. al-An'ām [6]: 139

${ }^{49}$ QS. Maryam [19]: 51; QS. Yūsuf [12]: 24; QS. al- Ḥijr [15]: 40; QS. al-Șāffāt [37]: 40, 74, 128, 160, 169; dan QS. Șād [38]: 83. 
bertentangan dengan isi kandungan surat. Makna khalasha dan derivasinya yang berkaitan dengan agama juga mengalami perkembangan di era pasca pewahyuan. Berikut medan semantik penggunaan lafaz khalasha dan derivasinya dalam Alquran.

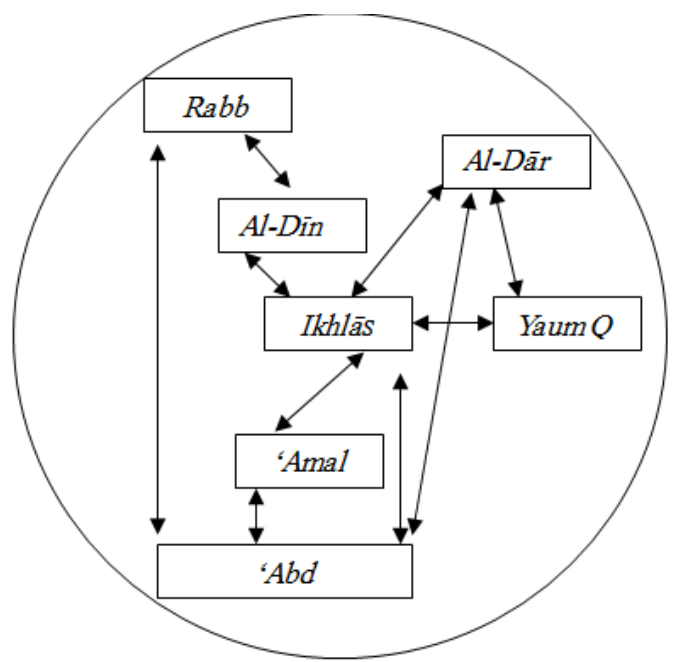

Bagan 1 Medan Semantik

\section{Post Quranik}

Setelah mendiskusikan tentang bagaimana konsep tersebut pra dan pada masa Alquran turun, aspek terakhir dari analisis sinkronik dan diakronik ialah aspek pasca Quranik. Konsep pasca Quranik, dimulai dari masa kbulafaurrasyidin hingga saat ini. Tentu, melacak pendapat para cendekiwan dalam karya tafsir mereka sangat dibutuhkan dalam aspek ini. Dalam hal ini, penulis memaparkan derivasi khalasha dari kedua bentuk konsepnya, yakni bentuk yang merujuk terhadap suatu sesuatu (thing) dan bentuk yang merujuk terhadap agama (religion).

Perkembangan makna terus terjadi di era pasca pewahyuan. Misalnya tafsir terhadap mukblishin labu al-dìn dalam QS. Gafir [40]: 65. Muqātil bin Sulaimān (w. $150 \mathrm{H}$ ) -mufasir klasik- dan al-Samarqandī (w. $373 \mathrm{H}$ ) menafsirkan kata mukblishin dengan kata al-muwabbidin (orang-orang yang menauhidkan) dan al-dìn dengan al-taubid. ${ }^{50}$ Sedangkan Menurut al-Qurthubī (w.

${ }^{50}$ Abu al-Hasan Muqatil ibn Sulaiman, Tafsir Ibn Muqatil (Beirut: Dar Ihya' al-Kutub al'Lmiyah, 2003), 3, 154; Nashr al-Din Muhammad bin Ahmad Abu al-Laits al-Samarqandi, Tafsir Bahr Al-'Ulum (Beirut: Dar al-Kutub al-'Tlmiyah, 2006), 3, 172. 
$671 \mathrm{H})$, lafaz mukblishin bermakna taat dan ibadah. ${ }^{51}$ Dilain sisi, menurut alBaidhawī (w. 685 H), al-Nasafī (w. 710 H), Abū Hayyān (w. 745 H), Abū Sưūo (w. $982 \mathrm{H}$ ), dan al-Alūsī (w. $1270 \mathrm{H}$ ) lafaz mukblishin bermakna taat dan meningalkan perbuatan sirik dan riyaa ${ }^{52}$ Ibn Katsìr (w. 774) sependapat dengan Ibn Sulaimān. ${ }^{53}$ Lebih jelasnya perhatikan skema berikut:

\section{Skema Perkembangan makna ikhlāṣ}

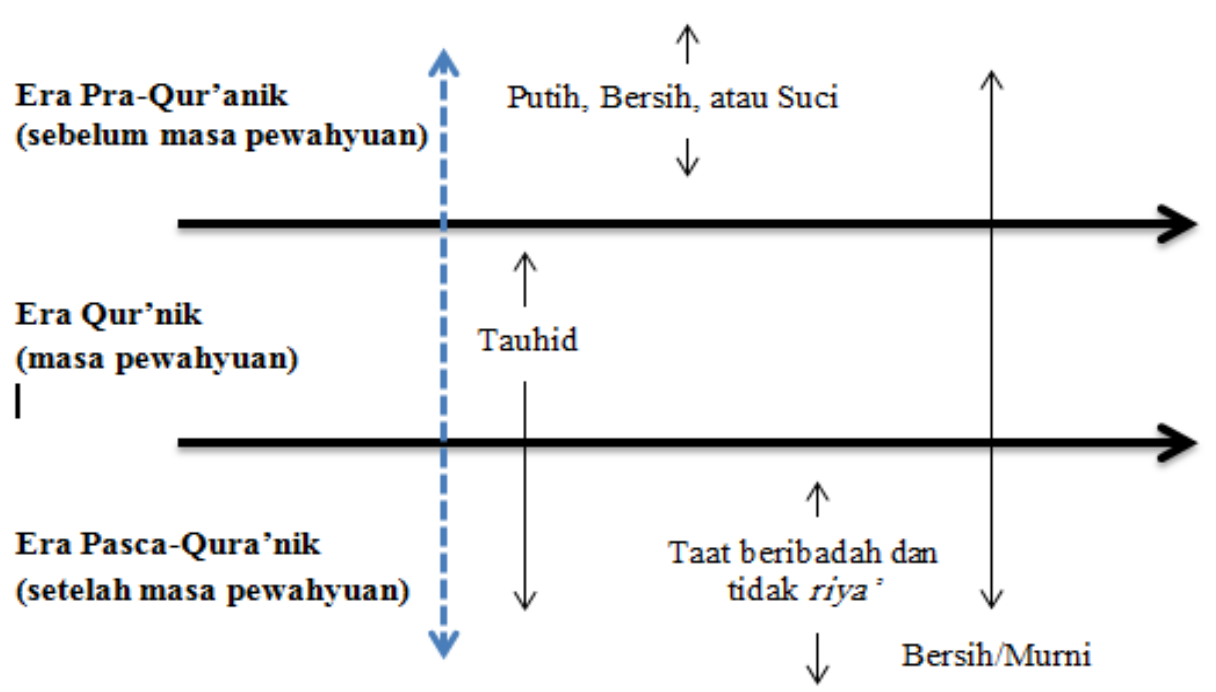

\section{Kesimpulan}

Dari penelitian ini dapat disimpulkan bahwa, pertama, makna dari khalasha yaitu memurnikan. Sedangkan makna relasionalnya bisa menjadi jernih, bersih, khusus, mengesakan, dan menauhidkan. Kedua, di era sebelum Alquran turun, lafaz khalasha dan derivasinya dalam Alquran digunakan untuk menunjuk air jernih dan bersih, baju putih yang indah, unta yang gemuk, dan suatu yang tidak bernoda. Ketiga, dalam Alquran kata ini menunjuk ke arah dua konsep, agama dan benda. Kata Khalasha jika berhubungan dengan term al-din (agama),

${ }^{51}$ Abî 'Abdillah Muhammad bin Ahmad bin Abî Bakr Al-Qurtubî, Al-jâMi' Li Ahkâm Al-Quran Wa Al-Mubayyin Lima Tadammanabu Min Al-Sunnab Wa Ay Al-FurqâN (Beirut: Muassasah al-Risâlah, 2001), 15, 326.

${ }^{52}$ Nashr al-Din Abu Sa'id Abdullah Abu Amr Muhammad al-Sairazy Al-Baidhawi, Anwar Al-Tanzil Wa Asrar Al-Ta'wil (Beirut: Dar al-Fikr, 1996), 5, 99; al-Alusi, Ruh AlMa'ani Fi Tafsir Al-Qur'an Al- 'Azhim, 88; Abu Birkat 'Abdullah bin Ahmad bin Mahmud al-Nasafi, Madarik Al-Tanzīl Wa Haqaiq Al-Ta'wil (Libanon: Dar Nafais, 1996), 4, 119; Abu al-Su'ud Muhammad al-Amadi, Tafsir Abi Su 'Ud (Beirut: Dar Ihya' Turats al-'Arabi, 1994), 7, 285.; ibn Ya'qub, Qamus Al-Muhith, 7, 454.

53 Abu al-Fida Ismāil bin KaSìir al-Dimasyqīi, Tafsìr al-Qur'ān al' Ažìm (Beirut: Dār Iḥya alTurās̀ al-'Arabī, 1985), juz 7, hlm. 141. 
bermakna tauhid. Sedangkan jika berhubungan dengan sebuah benda (thing), maka bermakna bersih. Keempat, pasca Alquran kata tersebut mengalami perkembangan, seperti agar menghindari syirik, melakukan dengan ibadah karena Allah agar tidak riya, dan taat beribadah.

\section{Bibliografi}

Abdul Baqî, Muhammad Fuad. Al-Mu'jam Al-Mufahras Li Alfað̧ Al-Quran AlKarim Bi Hasyiah Al-Mushaf Al-Syarifah. Kairo: Dar al-Hadis, 2001.

Abu Zaid, Nasr Hamid. Tekstualitas Alquran: Kritik Terbadap Ulumul Quran. Yogyakarta: LKis, 2001.

Al-Baidhawi, Nashr al-Din Abu Sa'id Abdullah Abu Amr Muhammad al-Sairazy. Anwar Al-Tanzil Wa Asrar Al-Ta'wil. Beirut: Dar al-Fikr, 1996.

Al-Qurtubî, Abî 'Abdillah Muhammad bin Ahmad bin Abî Bakr. Al-jâMi' Li Abkâm Al-Quran Wa Al-Mubayyin Lima Tadammanahu Min Al-Sunnah Wa Ay Al-FurqâN. Beirut: Muassasah al-Risâlah, 2001.

Alusi, Muhammad bin 'Abdullah al-Husaini al-. Rub Al-Ma'ani Fi Tafsir AlQur'an Al-'Az̧im. Beirut: Dar Ihya' Turats al-'Arabi, 1985.

Amadi, Abu al-Su'ud Muhammad al-. Tafsir Abi Su Ud. Beirut: Dar Ihya' Turats al-'Arabi, 1994.

Darwisy, Muhy al-Din al-. I'rab Al-Qur'an Al-Karim Wa Bayanuh. Beirut: Dar Ibn Kasir, 1999.

Faris, Ahmad ibn. Mu'jam Maqayis Al-Lughah. Beirut: Dar Ihya' Turats al-'Arabi, 2001.

Gros, Steen. "Externalism in Semantics." In The Routledge Handbook of Semantics, edited by Nick Riemer. New York: Routlegde, 2016.

Hanafi, Wahyu. "Linguistik Al-Qur'an (Reinterpretasi Makna Manusia Di Balik Surat Al-FâTihah Dalam Wacana Semantik)." Studia Quranika: Jurnal Studi Quran 2, no. 1 (2017). doi:10.21111/studiquran.v2i1.1131.

Izutsu, Toshihiko. Relasi Tuban Dan Manusia: Pendekatan Semantik Terbadap Alquran. Yogyakarta: Tiara Wacana, 2003.

Khulli, Amin al-. "Tafsir." In Pemikiran Hermeneutika Dalam Tradisi Islam: Reader, by Syafaatun Mirzanah and Sahiron Syamsuddin. Yogyakarta: Lembaga Penelitian, UIN Sunan Kalijaga, 2011.

Manzhur, Ibnu. Lisan Al-'Arab. Beirut: Dar al-Kutub al-Ilmiyah, 2009. 
124 | AL QUDS : Jurnal Studi Alquran dan Hadis vol. 2, no 2, 2018

Muqatil ibn Sulaiman, Abu al-Hasan. Tafsir Ibn Muqatil. Beirut: Dar Ihya' alKutub al-'Lmiyah, 2003.

Nasafi, Abu Birkat 'Abdullah bin Ahmad bin Mahmud al-. Madarik Al-Tanæīl Wa Haqaiq Al-Ta'wil. Libanon: Dar Nafais, 1996.

Samarqandi, Nashr al-Din Muhammad bin Ahmad Abu al-Laits al-. Tafsir Babr Al-'Ulum. Beirut: Dar al-Kutub al-'Ilmiyah, 2006.

Shalih, Bajat 'Abd al-Wahid. Al-I'rab Al-Mufashshal Li Kitab Allah Al-Murrattal. Beirut: Dar al-Fikr, n.d.

Ya'qub, Al-Fairuz Zabadi Muhammad ibn. Qamus Al-Mubith. Beirut: Muassasah al-Risalah, 1993. 